Research Paper

\title{
Antimicrobial Susceptibilities of Brucella Isolates from Various Clinical Speciemens
}

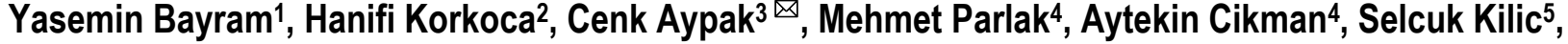 \\ Mustafa Berktas 4
}

1. Van Education and Research Hospital, Department of Microbiology, 65100 Van, Turkey.

2. Muş Alparslan University, School of Health, Department of Nursing, 49100 Muş, Turkey.

3. Van Gevaş Hospital, Department of Family Medicine, 65110 Van, Turkey.

4. Van 100. Yil University, Department of Microbiology, 65100 Van, Turkey.

5. Refik Saydam National Hygiene Center, Department of Communicable Diseases Research, 06100 Ankara, Turkey.

Corresponding author: Van Gevas Hospital, Department of Family Medicine, 65110, Van, Turkey. cenkaypak@yahoo.com; Tel: +90 505 6452780; Fax: +90 4326122066

(C) Ivyspring International Publisher. This is an open-access article distributed under the terms of the Creative Commons License (http://creativecommons.org/ licenses/by-nc-nd/3.0/). Reproduction is permitted for personal, noncommercial use, provided that the article is in whole, unmodified, and properly cited.

Received: 2010.12.16; Accepted: 2011.02.23; Published: 2011.03.03

\begin{abstract}
Purpose: Brucellosis is a worldwide zoonotic disease and still constitutes a major public health problem. In the study we claimed to identify Brucella species from clinical samples of patients with active brucellosis from Van region of Eastern Anatolia and to determine in vitro antimicrobial susceptibilities of these strains to commonly used anti-Brucella agents and a possible new alternative tigecycline.

Materials and Methods: A total of 56 Brucella isolates were enrolled the study and the identification of the isolates were based on conventional methods. In vitro activities of antimicrobials were evaluated by the $E$ test method.

Results: All isolates were identified as B. melitensis. MIC $_{90}$ values of doxycycline, streptomycin, rifampin, trimethoprim-sulfamethoxazole and tigecycline were $0.064 \mathrm{mg} / \mathrm{L}, \mathrm{I} \mathrm{mg} / \mathrm{L}, 2$ $\mathrm{mg} / \mathrm{L}, 0.125 \mathrm{mg} / \mathrm{L}$ and $0.094 \mathrm{mg} / \mathrm{L}$, respectively. Tigecycline had low $\mathrm{MIC}_{50}$ and $\mathrm{MIC}_{90}$ values against all $B$. melitensis strains; the highest MIC observed was $0.25 \mu \mathrm{g} / \mathrm{mL}$.

Conclusion: Our data suggest that tigecycline can be a therapeutic alternative option for the treatment of brucellosis.
\end{abstract}

Key words: Brucella, antimicrobial susceptibility, E-test, tigecycline

\section{Introduction}

Human brucellosis remains the most common zoonotic disease worldwide, with more than 500,000 new cases annually [1]. It is caused by Gram-negative bacteria, Brucella spp. and is transmissible to humans through direct contact with infected animals, consumption of dairy products, or inhalation of aerosols [2].

Brucellosis is a multisystemic disease that shows wide clinical polymorphism. Its main clinical signs are fever, headache, anorexia, fatigue, arthritis, hepatosplenomegaly, and neurological signs [2]. The disease represents serious consequences for public health by long treatment, slow recovery and possible serious sequelae in the locomotive and nervous system [2]. Although brucellosis has been eradicated in many northern European countries, in Australia, New Zealand, and Canada due to the implementation of national surveillance program and vaccination of live- 
stock, it is still hyperendemic in the Mediterranean basin, Middle East, Southwest Asia and parts of Latin America [1,3].

In Turkey, brucellosis is common, especially in East and Southeast Anatolia regions [4,5]. Among high-risk patients in the Eastern part of Turkey, seropositivity has been reported to be as high as $27.2 \%$ [6], but there have been no extensive studies done on the identification of Brucella species in this hyperendemic part of Anatolia.

The genus Brucella is an intracellular bacterial pathogen that infects host macrophage cells. In consequence, specialized agents that are able to penetrate the macrophages and function within their cytoplasm are required for the treatment of brucellosis [2]. Therefore, a limited number of antibiotics are effective against these organisms. In 1986, the WHO has released recommendations for use of doxycycline, combined with either rifampin or streptomycin for treating human brucellosis [7]. Although this recommendation is still in function and Brucella isolates are generally considered susceptible to the recommended by the WHO antibiotics, sporadic cases of a kind of antibiotic resistance have been reported [8,9]. Up until 2006, in vitro antimicrobial suspectibility testing of Brucella spp is not standardised and not generally recommended due to risk of laboratory-acquired infection and requirement of biological safety level 3 precautions, so there are few studies on this issue in the literature [8-16]. Furthermore in vitro susceptibilities of these antibiotics may change over time and from one geographical region to another $[17,18]$.

The side-effects of drug combination schemes, and the high incidence of relapses and therapeutic failures, have led to the investigation of new drugs to treat the disease. Fluoroquinolones, macrolides and tigecycline (TIG), a member of a new class of antimicrobials, the glycylcyclines, may serve as alternative drug choices [12-16].

This study aimed to find the most common Brucella species in this endemic region of Turkey since strategies for disease control and eradication derive primarily from the epidemiological characteristics of the disease and to determine the in vitro antimicrobial susceptibilities of these strains to commonly used anti-Brucella agents and a possible new alternative tigecycline.

\section{Materials and Methods}

Bacterial Strains: 56 Brucella isolates were collected prospectively between 2008-2009 from blood (45), synovial fluid (8), bone marrow (2), and cere- brospinal fluid (1) cultures of patients with acute brucellosis who were admitted to Van Education and Research Hospital and the hospital of the Medical Faculty of Van Yuzuncu Yil University (Van, Turkey).

Identification methods: Identification of species was made on the basis of the requirement of $\mathrm{CO}_{2}$ for growth, production of urease and $\mathrm{H}_{2} \mathrm{~S}$, sensitivity to the dyes basic fuchsine and thionine (at final concentrations of $20-40 \mu \mathrm{g} / \mathrm{ml}$ ), and agglutination with monospecific antisera for $\mathrm{A}$ and $\mathrm{M}$ antigens [19]. The strains were stored in skim milk at $-40^{\circ} \mathrm{C}$ and subcultured twice before the susceptibility tests.

Antimicrobial susceptibility testing: Minimum inhibitory concentration (MIC) of doxycycline (DOX), rifampin (RIF), streptomycin (STR), tigecycline (TIG) and trimethoprim-sulfamethoxazole (TMP-SMZ) were determined by E-test (Biomerieux, Sweden) method on Mueller-Hinton agar (Oxoid, Basingstoke, UK) supplemented with 5\% sheep blood and interpreted after 48 hours of incubation at ambient air. Mueller-Hinton agar supplemented with 5\% sheep's blood was inoculated with suspensions of the test organism equivalent $0.5 \mathrm{McF}$ arland turbidity, and E-test strips were applied onto culture plates. The plates were incubated in ambient air at $35^{\circ} \mathrm{C}$ and read after 48 hours. The MIC was interpreted as the value at which the inhibition zone intercepted the scale on the E-test strip. $\mathrm{MIC}_{50}$ and $\mathrm{MIC}_{90}$ levels defined as the lowest concentration of the antibiotic at which $50 \%$ and $90 \%$ of the isolates inhibited, respectively. The Clinical Laboratory Standarts Institute (CLSI; formerly the NCCLS) breakpoints for TMP-SMZ, STR, DOX were employed for the results. Three Brucella reference strains (B. abortus 544, B. melitensis $16 \mathrm{M}$, and $B$. suis 1330) were used as controls for identification, biotyping and antimicrobial susceptibility testing. In addition to these Brucella reference strains, Esherichia coli ATCC 25922, Staphylococcus aureus ATCC 29213 were also used as the quality control strain for susceptibility testing.

\section{Results}

All isolates were identified as B. melitensis. In vitro activities of DOX, STR, RIF, TMP-SMZ, and TIG against these isolates were evaluated.

The MIC values of DOX, STR and TMP-SMZ interpreted according to the CLSI criteria for potential bioterrorism agents and interpretive criteria for slow growing bacteria (Haemophilus) has been used to evaluate the results of MICs of TIG. The MIC 50 and $\mathrm{MIC}_{90}$ values of relevant antibiotics are shown in Table 1 . 
Table I. MIC range, $\mathrm{MIC}_{50}$ and $\mathrm{MIC}_{90}$ values of antimicrobial agents.

\begin{tabular}{|c|c|c|c|c|c|c|}
\hline \multirow[t]{2}{*}{ Antimicrobial } & \multicolumn{3}{|c|}{ E-test MIC $(\mu \mathrm{g} / \mathrm{ml})$} & \multicolumn{3}{|c|}{ CLSI breakpoints $(\mu \mathrm{g} / \mathrm{ml})$} \\
\hline & MIC ranges & $\mathrm{MIC}_{50}$ & $\mathrm{MIC}_{90}$ & S & I & $\mathrm{R}$ \\
\hline $\mathrm{DOX}^{\mathrm{a}}$ & $0.023-0.125$ & 0.047 & 0.064 & $\leq 1$ & - & - \\
\hline $\mathrm{TIG}^{\mathrm{b}}$ & $0.019-0.25$ & 0.064 & 0.094 & $\mathrm{ND}^{\mathrm{f}}$ & & \\
\hline TMP/SMZc & $0.064-0.25$ & 0.064 & 0.125 & $\leq 2$ & - & - \\
\hline $\mathrm{STR}^{\mathrm{d}}$ & $0.064-1.5$ & 1 & 1 & $\leq 8$ & - & - \\
\hline RIFe & $0.5-2.0$ & 1.5 & 2 & $\mathrm{ND}^{\mathrm{f}}$ & & \\
\hline
\end{tabular}

a:Doxycycline; b: Tigecycline; c: Trimethoprim/ sulfamethoxazole (only the trimethoprim portion of the $1 / 19$ drug ratio is displayed); d:Streptomycin; e: Rifampin;

f: not displayed in CLSI table for Brucella spp.

According to $\mathrm{MIC}_{90}, \mathrm{DOX}(0.064 \mu \mathrm{g} / \mathrm{ml})$ was found to be the most active agent, followed by TIG (0.094 $\mu \mathrm{g} / \mathrm{ml})$, TMP-SMZ (0.125 $\mu \mathrm{g} / \mathrm{ml})$, STR (1 $\mu \mathrm{g} / \mathrm{ml})$ and RIF $(2 \mu \mathrm{g} / \mathrm{ml})$ respectively. All isolates were found to be sensitive to DOX, STR and TMP-SMZ. The MIC values of TIG interpreted according to the CLSI criteria for slow growing bacteria, has shown ranges below the breakpoints for sensitivity determination. The highest MIC of TIG against Brucella isolates was $0.25 \mu \mathrm{g} / \mathrm{ml}$.

\section{Discussion}

Brucellosis is endemic in Turkey and approximately 10,000 cases of human brucellosis are reported annually [5]. Brucellosis and its complications are still serious public health concern in Eastern Anatolia. Although the diagnosis of brucellosis can be made only by the isolation of causative agent; Brucella spp. are difficult to isolate and the procedures are time consuming and expensive [8,20]. Moreover, Brucella spp. are so highly infectious that the attempts at isolation and identification of Brucella from clinical specimens are not routinely performed [8,20-22]. Therefore, the epidemiology of brucellosis has not been extensively studied, and limited data are available about the prevalence and species most commonly encountered in Eastern Anatolia. This is the first study which identifies Brucella species and their susceptibility pattern in this region. Our findings are in accordance with the previous reports from different regions of Turkey, Mediterranean and South America basin which have revealed that human brucellosis is almost exclusively caused by B.melitensis, accounting for $99 \%$ of total cases [8-16,22-25].

In this present study, we also performed in vitro susceptibilities of B.melitensis against commonly used antimicrobials and a novel compound tigecycline. Antimicrobial susceptibility testing for Brucella spp is not generally recommended for routine microbiology laboratories except in life-threatening organ involvement, and in case of treatment failure and relapse [21]. Another problem with such testing is the lack of standardization. Methods for MIC determination are described for potential bioterrorism agents including Brucella species by the CLSI. The CLSI proposes the microbroth dilution method using Brucella broth for Brucella spp. The breakpoints used for interpretation as susceptible were as follows: TET/DOX $\leq 1 \mu \mathrm{g} / \mathrm{ml}$, TMP-SMZ $\leq 2 \mu \mathrm{g} / \mathrm{ml}$, and STR $\leq 8 \mu \mathrm{g} / \mathrm{ml}$ according to the the CLSI interpretive criteria [26]. In vitro efficacy of antibiotics against Brucella spp. has usually been based on the determination of MIC values by micro broth dilution, agar dilution, and E-test methods [20]. E-test method was found to be reliable, reproducible, less labor-intensive, less time-consuming, and more practical than the broth micro dilution method $[11,24,27]$. Therefore E-test method was used in this study. E-test could be performed on two different culture media: the Mueller-Hinton agar plates widely used for antibiotic susceptibility testing and the Brucella agar plates commonly used in the laboratory as Brucella growth medium. Although no significant differences were observed between two culture media, we preferred the Mueller-Hinton agar plate in this study because clearer inhibition zones are visible and the calibrated carrier strip indicating the MIC can be more easily read [25].

TET and its derivatives are among the most effective drugs against brucellosis [2]. DOX has become the most commonly prescribed tetracycline derivative in the treatment of brucella infections because of its superior pharmacokinetic features [28]. In the present study, among the tested antibacterial agents, DOX was found to have the lowest MIC $_{50}$ and MIC $_{90}$ values which is consistent with previous reports $[8,10,11,22-24,27,29]$. Conversely in a Mexican study, Lopez-Merino et al. found the MIC values for TET were higher than in Brucella strains isolated in Turkey [9] which demonstrates the antibiotic susceptibility 
patterns of Brucella strains appear to vary geographically.

Another drug of choice in the treatment regimen of brucellosis is RIF and it was found to be the only antibiotic with increased activity in acidic environmental conditions [27]. In our study, the highest MIC values were determined for RIF among the studied antimicrobials. As MIC values of RIF in previous studies were reported to range from 0.047 to $4 \mu \mathrm{g} / \mathrm{ml}$, its values confirmed again by our findings [8,10-12,22-25]. Memish et al. reported an in vitro resistance rate of $3.5 \%$ for RIF [31]. These findings should be taken into consideration for the potential emergence of RIF resistance of Brucella spp. in the region. Another concern for RIF using widespread in the long treatment regimens like brucellosis may cause an increase in RIF resistance in $M$. tuberculosis because both brucellosis and tuberculosis can simultaneously exist in the same countries in many parts of the world [32]. Furthermore experimental studies suggested that the development of mycobacterial resistance to RIF may lead to development of resistance to other antimicrobials as well [32]. The resistance rate of RIF against $M$. tuberculosis was reported as $15-58 \%$ in Turkey [33]. The burden of such resistance for public health must be considered.

TMP-SMZ containing regimens is considered to be suitable oral regimens that may be of significantly lower cost than traditional combinations in certain developing countries and mostly prescribed in brucellosis for children and pregnant women [2]. In our study $\mathrm{MIC}_{50}$ and $\mathrm{MIC}_{90}$ values for TMP-SMZ were lower than those previously observed in Turkey $[8,10,11]$ and conforming the results of Kilic et al. [16]. In vitro TMP-SMZ resistance rate was reported $2 \%$ in Turkey [8]. However, significant rates of TMP-SMZ resistance have been reported in the world [31,34].

Although streptomycin is known to be one of the most active agent against brucellosis, its adverse effects, such as ototoxicity, nephrotoxicity, and parenteral administration, preclude its wider use $[24,29]$. In our study susceptibility to STR was found to be in the range described previously $[8,10,12,24,29]$.

This is one of the few studies which, determines the in vitro activity of TIG, a new glycylcycline compound, against Brucella strains. We found that TIG was more effective than RIF, TMP-SMZ and STR but was not as effective as DOX. Dizbay et al. reported TIG was more effective than RIF, SXT, STR, and DOX [8]. Also Kilic et al. found TIG had the least $\mathrm{MIC}_{50}$ and $\mathrm{MIC}_{90}$ values compared to TET, and fluoroquinolones against Brucella strains isolated in Central Anatolia [13]. These are in contrast with our findings and might be due to the strain specific susceptibility. As $\mathrm{MIC}_{50}$ and $\mathrm{MIC}_{90}$ values of TIG in these two previous studies were reported to be 0.064 and $0.125 \mu \mathrm{g} / \mathrm{ml}$ respectively, values of them confirmed again by our findings.

Although TIG has similar properties to TET, it has been reported that it is more potent than TET $[35,36]$. TET is the mainstay of anti-brucellosis regimen. Therefore, Pappas et al. suggested replacing DOX with more potent TIG might increase efficacy and reduce treatment duration [37]. On the other hand, parenteral administration of TIG, the conservation of TIG because of promising results of its use in the treatment of multiresistant bacterial infections, and overall cost were considered as limitations of such a therapy [12].

In conclusion, there is no significantly important resistance problem for classically recommended antibiotics targeted to Brucella species in Turkey, but antibiotic susceptibility patterns of Brucella spp. appear to vary geographically. Therefore, we suggest, regional periodic assessment of susceptibility of strains to antimicrobials. The results of this in vitro study suggest TIG as a therapeutic option in the treatment of brucellosis. Clinical trials are warranted to assess the real therapeutic potential of TIG in human brucellosis, particularly in countries with higher prevalence of antibiotic resistance.

\section{Conflict of Interest}

The authors have declared that no conflict of interest exists.

\section{References}

1. Pappas G, Papadimitriou P, Akritidis N, Christou L, Tsianos EV. The new global map of human brucellosis. Lancet Infect Dis. 2006; 6:91-99.

2. Young EJ. Brucella species. In: Mandell GL, Bennett JE, Dolin R, eds. Principles and practice of infectious diseases, 6th ed. Philadelphia: Churchill Livingstone; 2005: 2669-2672.

3. Black TF. Brucellosis. In: Cohen J, Powderly WG, eds. Infectious diseases; 2nd ed. St Louis: Mosby; 2004: 1665-1667.

4. Doğanay M, Meşe-Alp E. In: Topçu AW, Söyletir G, Doganay $\mathrm{M}$, eds. Infeksiyon hastalıkları ve mikrobiyolojisi; 3rd ed. Istanbul: Nobel Tip Kitabevleri; 2008: 897-909.

5. Yüce A, Alp-Çavuş S. Türkiye' de bruselloz: genel bakış. Klimik derg 2006; 19:87-97.

6. Ceylan E, Irmak H, Buzgan T, Karahocagil MK, Evirgen Ö, Sakarya N, et al. Van iline bağlı bazı köylerde insan ve hayvan populasyonunda bruselloz seroprevalansi. Van Tip Derg. 2003; 10:1-5.

7. Joint Food and Agriculture Organization/World Health Organization. FAO-WHO Expert Committee on Brucellosis (sixth report). WHO Technical Report Series No. 740. Geneva: World Health Organisation; 1986: 56-57.

8. Baykam N, Esener H, Ergonul O, Eren S, Celikbas AK, Dokuzoguz B. In vitro antimicrobial susceptibility of Brucella species. Intern J Antimicrob Agents. 2004; 23:405-407.

9. Lopez-Merino A, Contreras-Rodriguez A, Migranas-Ortiz R, Orrantia-Gradin R, Hernandez-Oliva GM, Guttierrez-Rubio 
AT, Cardenosa O. Susceptibility of Mexican brucella isolates to moxifloxacin, ciprofloxacin and other antimicrobials used in the treatment of human brucellosis. Scand J Infect Dis. 2004; 36:636-638

10. Bodur H, Balaban N, Aksaray S, Yetener V, Akinci E, Colpan A, Erbay A. Biotypes and antimicrobial susceptibilities of Brucella isolates. Scand J Infect Dis. 2003; 35(5):337-338.

11. Köse S, Kiliç S, Ozbel Y. Identification of Brucella species isolated from proven brucellosis patients in Izmir, Turkey. J Basic Microbiol. 2005; 45(4):323-327.

12. Dizbay M, Kilic S, Hizel K, Arman D. Tigecycline: its potential for treatment of brucellosis. Scand J Infect Dis. 2007; 39(5):432-434.

13. Kilic S, Dizbay M, Cabadak H. In vitro activity of tigecycline, tetracycline and fluoroquinolones against Brucella melitensis. J Chemother. 2008; Feb;20(1):33-37.

14. Garcia-Rodriguez JA, Garcia-Sanchez JE, Trujillano I. Lack of effective bactericidal activity of new quinolones against Brucella spp. Antimicrob Agents Chemother. 1991; 35:756-759.

15. Qadri SM, Halim MA, Ueno Y, Abumustafa FM, Postle AG. Antibacterial activity of azithromycin against Brucella melitensis. Chemotherapy. 1995;41(4):253-256.

16. Kilic S, Dizbay M, Hizel K, Arman D. In vitro synergistic activity of antibiotic combinations against Brucella melitensis using E-test methodology. Braz J Mic. 2008; 39:1-7.

17. De Rautlin de la Roy YM, Grignon B, Grollier G, Coindreau MF, Becq-Giraudon B. Rifampicin resistance in a strain of Brucella melitensis after treatment with doxycycline and rifampicin. J Antimicrob Chemother. 1986; 18:648-649.

18. Kinsara A, Al-Mowallad A, Osoba O A. Increasing resistance of Brucellae to co-trimoxazole. Antimicrob. Agents Chemother. 1999; 43:1531.

19. Alton GG, Jones LM, Angus RD, Verger JM. Techniques for the brucellosis Laboratory. Paris: Institut National de la recherche Agronomique (INRA). 1988; 34-61.

20. Shapiro SD, Wong JD. Brucella. In: Murray PR, Baron EJ, Pfaller MA, Tenover FC, Yolken RH, eds. Manuel of clinical microbiology, vol 1,7th ed. Washington DC: ASM Press; 1999: 625-631.

21. King A. Recommendations for susceptibility tests on fastidious organisms and those requiring special handling. J Antimicrob Chemother. 2001; 48 (Suppl S1): S77-S80.

22. Yamazhan $T$, Aydemir Ş, Tünger A, Serter D, Gökengin D. In vitro activities of various antimicrobials against Brucella melitensis strains in the Agean Region in Turkey. Med Princ Pract. 2005; 14: 413-416.

23. Ayaşlığlu E, Kılıç S, Aydın K, Kılıç D, Kaygusuz S, Ağalar C. Antimicrobial susceptibility of Brucella melitensis isolates from blood samples. Turk J Med Sci. 2008; 38(3): 257-262.

24. Turkmani A, Ionnidis A, Christidou A, Psaroulaki A, Loukaides F, Tselentis Y. In vitro susceptibilities of Brucella melitensis isolates to eleven antibiotics. Ann Clin Microbiol Antimicr. 2006; 5: 24.

25. Marianelli C, Graziani C, Santangelo C, Xibilia MiT, Imbriani A, Amato R, Neri D, Cuccia M, Rinnone S, Di Marco V, Ciuchini F. Molecular epidemiological and antibiotic susceptibility characterization of Brucella isolates from humans in Sicily, Italy. J Clin Microbiol. 2007; 45(9): 2923-2928.

26. Clinical and Laboratory Standards Institute. Performance standards for antimicrobial susceptibility testing; Sixteenth informational supplement; CLSI document M 100-S16. Wayne, PA, USA: CLSI. 2006.

27. Gür D, Kocagöz S, Akova M, Ünal S. Comparison of E test to microdilution for determining in vitro activities of antibiotics against Brucella melitensis. Antimicr Agents Chemother. 1999; 43(9): 2337.
28. Madkour MM. Treatment. In: Madkour MM, ed. Madkour's Brucellosis. 2nd ed. Berlin Heidelberg New York: Springer-Verlag; 2001: 241-261.

29. Rubinstein ER, Lang R, Shasha B, Hagar B, Diamanstein L, Joseph G, Anderson M, Harrison K. In vitro susceptibility of Brucella melitensis to antibiotics. Antimicrob Agents Chemother. 1991; 35:1925-1927.

30. Akova M, Gur D, Livermore DM, Kocagoz T, Akalin HE. In vitro activities of antibiotics alone and in combination against Brucella melitensis at neutral and acidic pHs. Antimicrob Agents Chemother. 1999; 43: 1298-1300.

31. Memish Z, Mah MW, Al Mahmoud S, Al Shaalan M, Khan MY. Brucella bacteraemia: clinical and laboratory observations in 160 patients. J Infect. 2000; 40(1):59-63.

32. Marianelli C, Ciuchini F, Tarantino M, Pasquali P, Adone R. Genetic bases of the rifampin resistance phenotype in Brucella spp. J Clin Microbiol. 2004; 42:5439-5443.

33. Kocabas A, Akciger T. In: Topçu AW, Söyletir G, Doganay M, eds. Infeksiyon Hastalıkları ve Mikrobiyolojisi. Istanbul: Nobel Tip Kitabevleri, 2002: 38-591.

34. Kinsara A, Al-Mowallad A, Osoba AO. Increasing resistance of Brucella to Co- Trimoxazole. Antimicrob Agents Chemother. 1999; 6: 1531.

35. Zhanel GG, Karlowsky JA, Rubinstein E, Hoban DJ. Tigecycline: a novel glycylcycline antibiotic. Expert Rev. Anti-Infect Ther. 2006; 4:9-25

36. Livermore DM. Tigecycline: what is it, and where should it be used? J Antimicrob Chemother. 2005; 56: 611-614.

37. Pappas G, Solera J, Akritidis N, Tsianos E. New approaches to the antibiotic treatment of brucellosis. Int J Antimicrob Agents. 2008; 26: 101-105. 